\title{
'n Nota oor die vertaling van Jeremia 2:37 (“Met jou hande op jou hoof')
}

H F Stander

(UP)

\section{ABSTRACT}

A note on the translation of Jeremiah 2:37 ("With your hands on your head")

In Jeremiah 2:37 God says to Israel: "You will leave that place (= Egypt) with your hands upon your head". In this article various Bible translations and commentaries are scrutinized to determine how modern exegetes interpret this phrase. Thereafter the author discusses Egyptian depictions of mourners in funeral processions with their hands on their heads. He shows how an exploration of Egyptian Art can contribute to a better understanding of Jeremiah 2:37. This study also shows that the two dynamic Afrikaans translations of the Bible ("Die Lewende Bybel" and "Die Nuwe Afrikaanse Vertaling") are wide off the mark in their interpretation of the phrase "with your hands on your head". The author also argues that exegetes should not only rely on written texts when they study the ancient world in which the Scriptures originated, but that they should also explore works of art.

\section{INLEIDING}

In Jeremia 2:37 sê God aan Israel: "Ook daarvan (= Egipte) sal jy uitgaan met jou hande op jou hoof". Wat presies beteken die frase "met jou hande op jou hoof"? Die Nuwe Afrikaanse Vertaling vertolk dit as 'n gebaar van ontevredenheid en vertaal die vers derhalwe soos volg "Jy sal daarvandaan terugkom sonder dat jy jou sin gekry het”. Die Lewende Bybel en Good News Bible beskou die frase "met jou hande op jou hoof" egter as 'n gebaar van skaamte. Daarom vertaal hulle dit onderskeidelik soos volg: "Julle sal julle gesig toehou van skaamte as julle teleurgesteld daar moet omdraai" en "You will turn away from Egypt, hanging your head in shame". Die Living Bible dink dit is 'n gebaar van wanhoop: "You will be left in despair and cover your face with your hands...". Dan is daar natuurlik talle ander vertalings wat die makliker uitweg volg en die frase bloot letterlik vertaal as "met jou hande op jou hoof". 
Voordat 'n mens enigsins verder die betekenis van hierdie gebaar ondersoek, is dit belangrik dat ons eers kyk na wat die breër verband is waarin dit voorkom:

In die eerste hoofstuk van die boek Jeremia lees ons hoe Jeremia geroep word om as profeet vir al die nasies op te tree (v. 5). In hoofstuk 2 kry ons die eerste boodskap wat die profeet Jeremia moet aflewer: Hy moet die volk Israel gaan herinner aan die tyd van Moses toe die volk nog getrou was aan God (ve. 1-3). Maar daarna het Israel afvallig geraak (ve. 4-13). Hulle het geleef asof God nie bestaan nie. Dit het nooit gebeur dat selfs heidennasies hul nikswerd afgode sou prysgee nie, maar God se volk, wat weet dat hierdie afgode niks beteken nie, was bereid om die lewende God te verruil vir daardie nuttelose afgode. Israel is nou geestelik bankrot terwyl hulle 'n oorvloed kon hê.

God sê verder dat beide Egipte en Assirië nog altyd net verwoesting en ongeluk oor Israel gebring het. Dit hou dus geen voordeel in vir Israel om hulle nou tot Egipte en Assirië te wend vir hulp nie (ve. 14-19). Nogtans loop hulle soos diere wat op hitte is, agter die Baäldiens aan (ve. 2325). Maar dit sal hulle nog duur te staan kom. 'n Mens kan God nie net vir die dag van nood bêre nie (ve. 26-28). Hulle sal vind dat wanneer 'n ramp hulle tref, God nie meer na hulle sal luister nie. Al is dit Israel wat ontrou geword het aan die Here, is hulle steeds nie bereid om dit te erken nie, en probeer hulle voortdurend om hulself te verontskuldig (ve. 29-35). Deur te weier om hul sonde te erken, bring hulle noodwendig straf oor hulself. Daarom sal God sorg dat hulle politieke bondgenootskappe met Egipte en Assirië misluk. So sal al hul planne op die rotse loop. Selfs Egipte sal hulle net so in die steek laat as wat Assirië dit gedoen het (v. 36).

Hierna volg vers 37 wat letterlik soos volg vertaal kan word: "Ook daarvan (= Egipte) sal jy uitgaan met jou hande op jou hoof; want die Here het hulle verwerp op wie jy vertrou, en jy sal met hulle geen voorspoed hê nie" (Ou Afrikaanse Vertaling).

\section{KOMMENTARE SE VERKLARING}

Talle kommentatore' ${ }^{1}$ gebruik 2 Samuel 13:19 (waar ons 'n soortgelyke uitdrukking teëkom) as 'n vertrekpunt vir hul verklaring van Jeremia 2:37. In 2 Samuel 13 lees ons hoe Amnon, die seun van Absolom, bloedskande met sy suster Tamar gepleeg het. Nadat Amnon sy suster onteer het, het hy egter 'n afkeer van haar gekry en haar weggestuur. Hierop het Tamar aan 
Amnon gesê: "Moenie die skande wat jy my aangedoen het, vererger deur my weg te jaag nie". Maar Amnon wou niks weet nie, en het sy slaaf beveel om "hierdie vroumens uit te smyt en die deur agter haar te sluit" (2 Sam 13:16-17). Dan lees ons die volgende woorde: "Tamar het as op haar hoof gestrooi en... (haar) lang rok met moue geskeur; daarby het sy haar hand op haar hoof gelê en aldeur geloop en weeklaag” (2 Sam 13:19).

Dit is waarskynlik met hierdie verhaal in die agterkop dat talle kommentatore die gebaar om "met jou hande op jou hoof" te loop, op soveel wyduiteenlopende wyses verklaar. Oosterhoff ${ }^{2}$ sien dit as "een gebaar van wanhoop en vertwijfeling", Aalders ${ }^{3}$ dink dit is 'n "teken van beschaming en ontsteltenis", terwyl Van Selms" dit weer as "teken van uiterste ontreddering" beskou. Die verklarende aantekeninge tot die Bijbel van die Nederlandsch Bijbelgenootschap5 verklaar die gebaar as simbool van "rouw, schaamte en schande". Osty en Trinquet ${ }^{6}$ sê die gebaar is "pour dissimuler ton visage couvert de confusion".

Jones ${ }^{7}$ sê dit is "a gesture of lamentation", terwyl The Interpreter's Bible ${ }^{8}$ dit as teken van "shame and dismay" verklaar. Clarke" sien dit as 'n bewys van "deep sorrow, occasioned by utter desolation". Jellie ${ }^{10}$ verklaar dit as "the general attitude of mourning", en Thompson" reken dit is "signs of grief". Gray beskou dit as 'n teken van "utter grief and despair"12. Green ${ }^{13}$ reken dit is tekens van "distress and disgrace".

Dit lyk inderdaad of die Nuwe Afrikaanse Bybelvertaling se interpretasie ("ontevredenheid omdat jy nie jou sin gekry het nie") ver buite die hoofstroom van interpretasies lê. Trouens, daar is geen ander bekende gesaghebbende Bybelvertalings wat hierdie interpretasie voorstaan nie.

\section{EGIPTIESE KUNS}

Dit is egter jammer dat dit so dikwels gebeur dat dit net geskrewe werke is wat betrek word wanneer agtergrondsmateriaal oor die antieke wêreld ingewin word met die oog op verantwoordelike eksegese van die Skrif. Ons durf nie die kunswerke van die antieke wêreld verwaarloos nie, omdat dit ook 'n waardevolle bydrae kan lewer tot ons verstaan van daardie wêreld en van die tekste wat in daardie tydvak ontstaan het. Die kommentatore hierbo sou byvoorbeeld baie daarby gebaat het indien hulle ook die Egiptiese kuns geraadpleeg het vir 'n beter verstaan van die uitdrukking "met jou hande op jou hoof"14. God sê mos juis in Jeremia 2:37 dat Israel uit Egipte sal uitgaan met hul hande op hul hoof.

Daar is talle voorstellings in Egiptiese kuns van mense wat "met hul hande op hul hoof" loop wanneer hulle hartseer is oor die dood van 'n 
geliefde of wanneer hulle in rou deelneem aan 'n begrafnisstoet. Hieronder (foto 1 ) is 'n reliëf van roubeklaers wat aan so 'n begrafnisprosessie deelneem. Almal loop met hul hande op hul hoof as teken van hul rou en smart. Hierdie beeldhouwerk kan tussen 650 en $630 \mathrm{vC}$ gedateer word, dit wil sê omtrent dieselfde tyd as wat die boek Jeremia ontstaan het (laasgenoemde het tussen 627 en $586 \mathrm{vC}$ ontstaan).

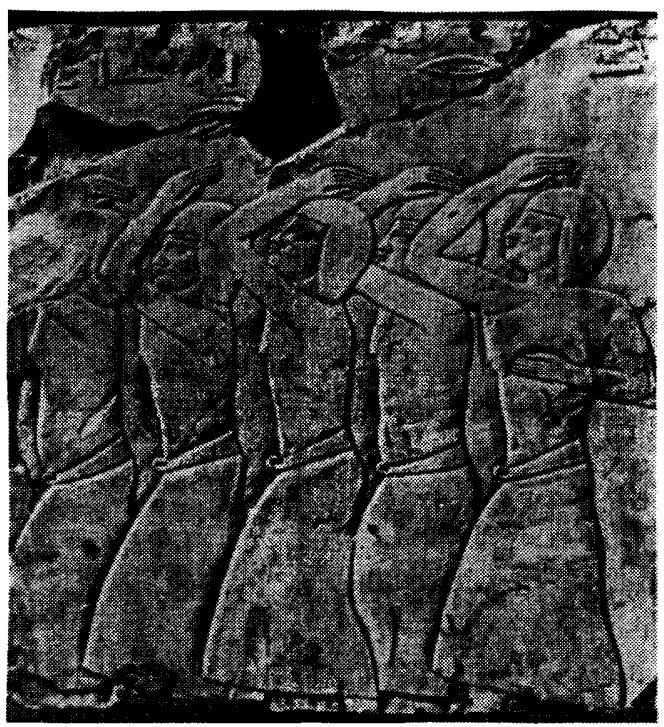

Foto 1: Roubeklaers wat aan ' $n$ begrafnisprosessie deelneem. Almal loop met hul hande op hul hoof as teken van hul rou en smart. 'n Reliëf van ongeveer $630 \mathrm{vC}$. 


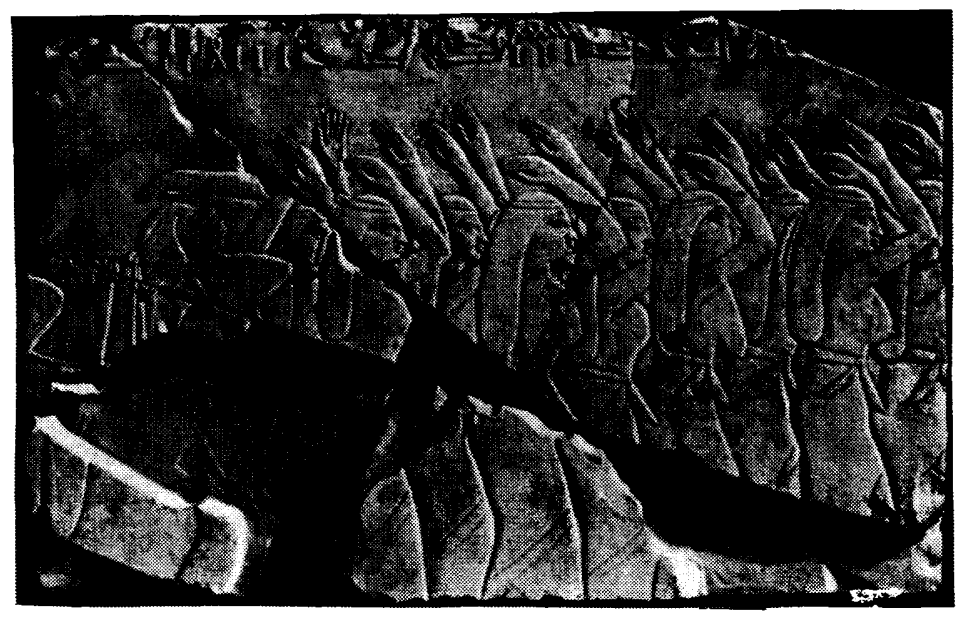

Foto 2: 'n Klompie vrouens wat loop en treur met hul hande op hul hoof by die begrafnis van 'n gestorwene. Reliëfwerk wat ongeveer $650-630 \mathrm{vC}$ gedateer moet word.

In foto 2 kry ons nog 'n uitbeelding van 'n klomp vrouens wat loop en treur by die begrafnis van 'n gestorwene. Hul klere en gelaatstrekke druk hartseer en rou uit, terwyl hul met hul hande op hul hoof loop. Die vrouens se borste is kaal, maar dit is nie deel van die rou-optrede nie, omdat dit heel algemeen was om so te loop. Ook hierdie reliëfwerk moet ongeveer 650-630 vC gedateer word. 


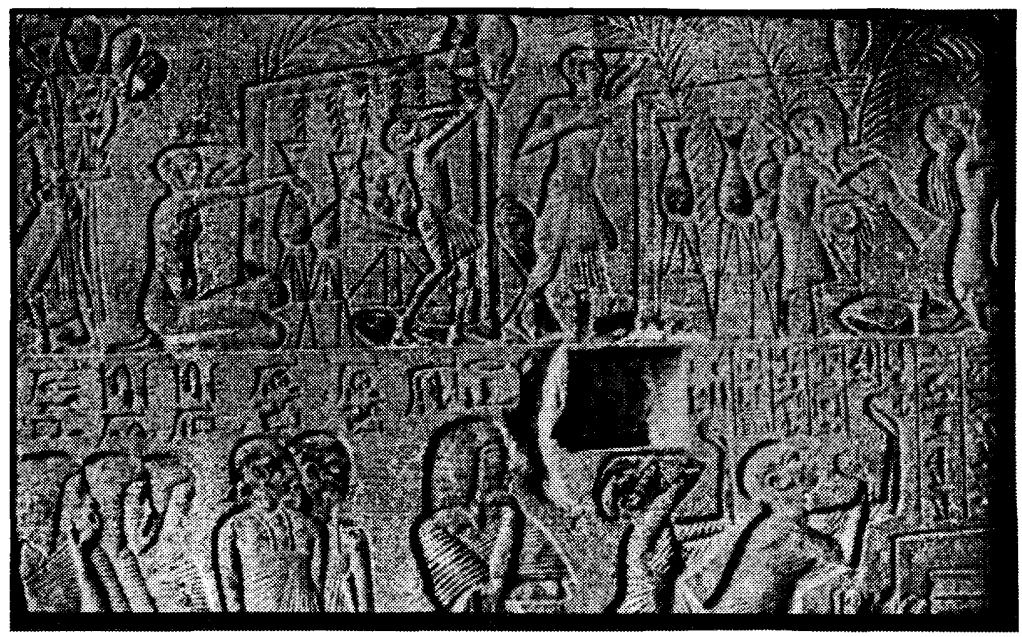

Foto 3: 'n Reliëfwerk (ongeveer $1300 \mathrm{vC}$ ) wat verskillende aspekte van begrafnisrites uitbeeld.

Die reliëfwerk ${ }^{15}$ in foto 3 beeld verskillende aspekte van begrafnisrites uit. Heel links bo is 'n blaarryke skuiling wat deur die diensknegte van die gestorwene opgerig is. Waterkruike staan in 'n houtraamwerk onder die skuiling. Dit is alles ter voorbereiding van die begrafnisrites. Heel regs bo word die skuiling afgebreek en die kruike stukkend gegooi na afloop van die begrafnis. In hierdie uitbeelding sien ons etlike figure met hul hande bo hul hoof. Sommige van die figure gee ook op ander wyses uitdrukking aan hul rou, soos ons op foto's 4 en 5 kan sien wat naderskote is van dieselfde reliëfwerk. In foto 4 word die voorarms vertikaal voor die persoon gehou, met die handpalms na voor gedraai. Die persoon in foto 5 sit gehurk met een hand oor sy hoof. Sy ander arm is na voor uitgestrek, terwyl sy hand slap hang om hulpeloosheid te suggereer te midde van die onverbiddelikheid van die dood. 


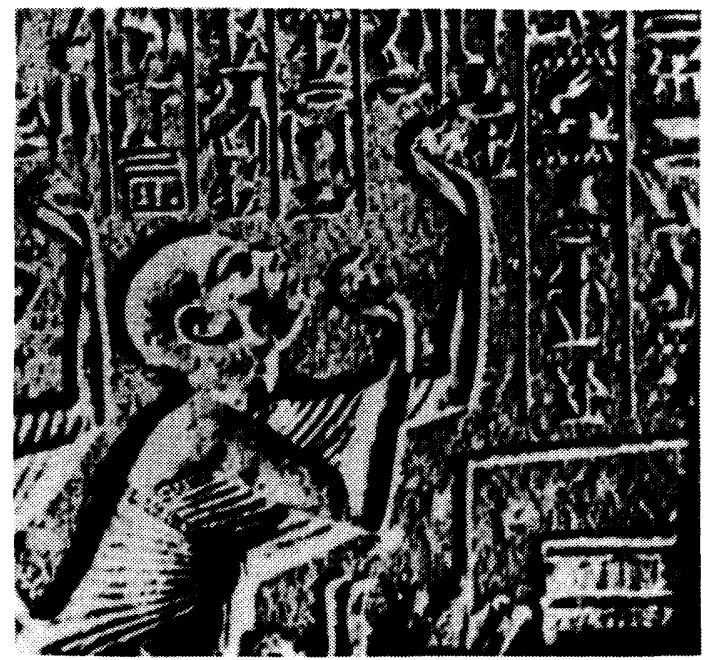

Foto 4: Die roubeklaer se voorarms word vertikaal voor die persoon gehou, met die handpalms na voor gedraai.

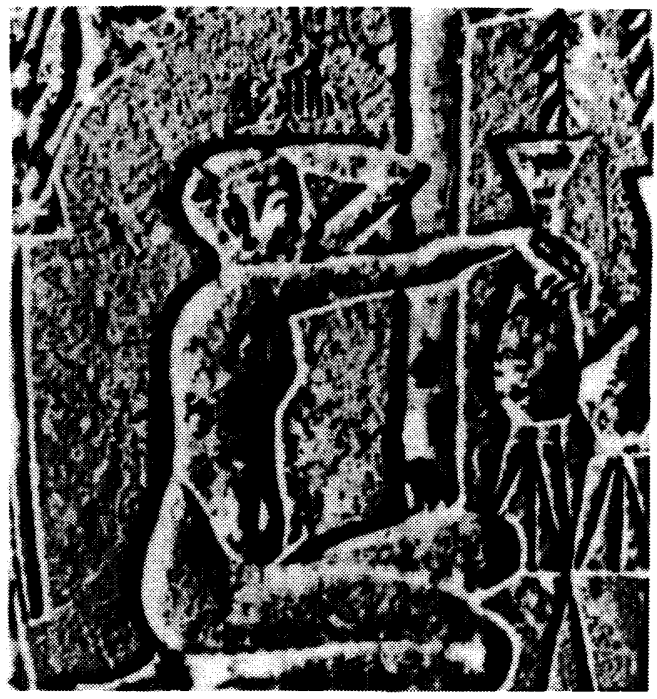

Foto 5: Die persoon sit gehurk met een hand oor sy hoof. Sy ander arm is na voor uitgestrek, terwyl sy hand slap hang om hulpeloosheid te suggereer. 


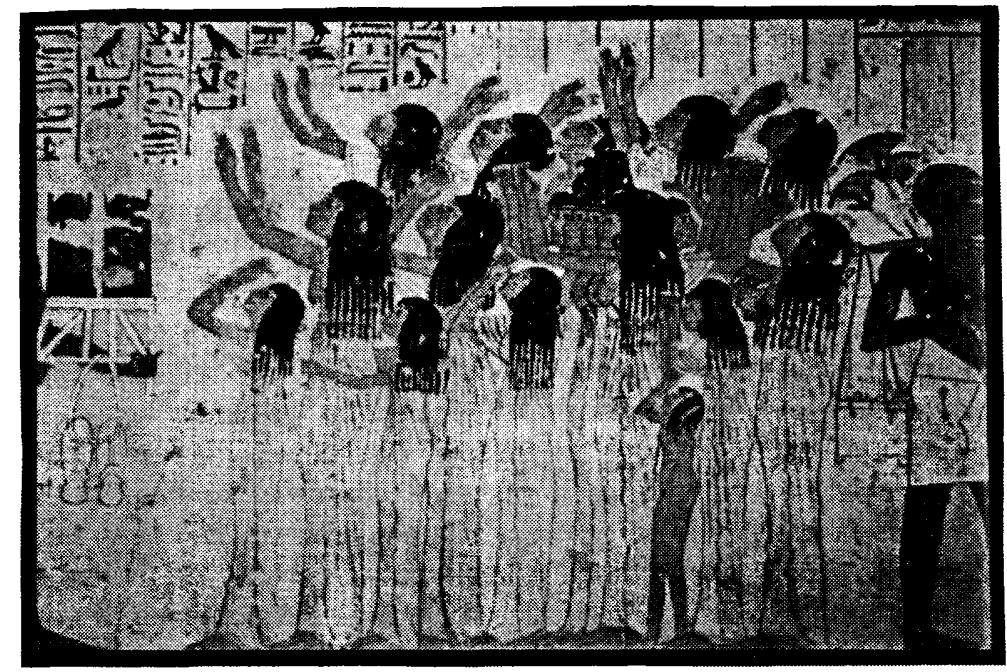

Foto 6: 'n Skildering van 'n klomp vrouens wat met ontblote borste rou en treur oor die dood van 'n persoon. Dit dateer waarskynlik uit die laat XVIIIe-dinastie.

In foto 6 het ons 'n skildering van 'n klomp vrouens ${ }^{16}$ wat weer eens met ontblote borste rou en treur oor die dood van 'n persoon. Hierdie vrouens druk hul smart met verskillende soorte gebare uit (insluitende deur hul hande op hul hoof te plaas). Ons moet nie die afleiding maak dat hierdie vrouens besig is om hul hoofde met hul hande te slaan nie. Die ander tonele wat hierbo bespreek is, wys dat ons veel eerder in hierdie skildering 'n voorstelling van verskeie aksies van rou het, soos om jou hande op jou hoof te plaas, of om jou hande voor jou uitgestrek te hou, met die handpalms hetsy na jouself gerig, of hetsy weg van jouself af.

\section{JEREMIA 2:37 IN DIE LIG VAN EGIPTIESE KUNS}

Ons kan dus sien dat dit 'n baie algemene gebruik in Egipte was om jou hand op jou hoof te plaas wanneer jy in rou en smart verkeer het. Dit is waarskynlik ook die betekenis wat hierdie uitdrukking in Jeremia 2:37 het. God sê aan Israel dat hulle hul rug op Hom keer, en dat hulle selfs met Egipte bondgenootskappe smee. Maar hulle gaan nog van Egipte af terugkom "met hul hande oor hul hoof", bedoelende in diepe rou en smart, 
want Egipte kon nie die hulp aan hulle verleen wat God altyd aan hulle geskenk het nie.

Dit is dus waarskynlik nie korrek om (soos ons hierbo gesien het) ook aspekte van "skaamte", "uiterste ontreddering", "skande" en "verwarring" in hierdie konteks in te lees nie. Wanneer 'n mens in 'n begrafnisprosessie loop, is die betekenisse van "skande" en "skaamte" tog nie van toepassing nie. Maar baie van hierdie betekenisskakerings is in Jeremia 2:37 ingedra op grond van die verhaal van Amnon se daad van bloedskande met sy suster Tamar in 2 Samuel 13:19. Maar dit is taalkundig nie korrek om op so 'n wyse enige woord (of 'n uitdrukking) se betekenis te bepaal nie. Linguiste definieer die betekenis van ' $n$ woord as die minimum bydrae wat 'n woord (of uitdrukking) tot die betekenis van 'n konteks maak ${ }^{17}$. Hierdie beginsels is nie net op geskrewe tekste van toepassing nie, maar ook op "kunstekste". Alhoewel die term "teks" gewoonlik gebruik word om na 'n geskrewe vorm van kommunikasie te verwys, kan dit bestaan uit enige teken of groep tekens ${ }^{18}$. Die term "teks" kan dus ook gebruik word om na 'n kunswerk te verwys. Dit is dan ook verder interessant om te sien hoeveel van die taalkundige beginsels wat in ag geneem moet word, wanneer geskrewe tekste interpreteer word, net so ook op kunstekste van toepassing is ${ }^{19}$.

Wanneer ons dus die uitdrukking (of voorstelling van) "hande op jou hoof" ondersoek, is dit belangrik dat 'n mens sal onderskei tussen die inligting wat ons uit die verhaal (of voorstelling) self haal en, aan die ander kant, die inligting wat die uitdrukking (of voorstelling) self aan ons oordra. 'n Mens kan dit eintlik redelik maklik bepaal deurdat jy probeer vasstel of die "betekenis" gemeenskaplik is aan al die tekste, en of dit net eie is aan een bepaalde teks. Wanneer ons dus 2 Samuel 13:19 (Amnon se daad van bloedskande) en Jeremia 2:37 (God se oordeel oor Israel) naas al die kunstekste hierbo plaas, vind ons dat die betekenis van "rou" en "smart" gemeenskaplik aan al hierdie tekste is. Die betekeniskomponente van "skande" en "skaamte" is net van toepassing in 2 Samuel 13:19. Ons moet dus aanneem dat laasgenoemde twee betekeniskomponente op grond van die verhaal van bloedskande in die uitdrukking ingelees word, terwyl die uitdrukking self slegs die komponente van "rou" en "smart" bevat.

\section{SLOTSOM}

In die lig van bogenoemde moet ons dus sê dat die Lewende Bybel se weergawe ("Julle sal julle gesig toehou van skaamte as julle teleurgesteld daar moet omdraai”) nie korrek is nie, terwyl die Nuwe Afrikaanse 
Bybelvertaling se interpretasie ("Jy sal daarvandaan terugkom sonder dat jy jou sin gekry het") geheel en al uit die kol is. Dit lyk dus eerder of Jeremia 2:37, in die lig van 2 Samuel 13:19 asook die etlike Egiptiese voorstellings hierbo, dinamies vertaal kan word as: "Ook daarvan (= Egipte) sal jy uitgaan in diepe smart en rou".

Hierdie artikel het ook weer eens die noodsaak daarvan onderstreep dat ons nie slegs geskrewe tekste moet betrek in ons bestudering van die agtergrond van die Skrif nie, maar dat kunswerke uit hierdie tyd ook 'n belangrike rol kan speel tot 'n beter verstaan van die Skrif.

\section{NOTAS:}

1 D R Jones, Jeremiah, NCB, Grand Rapids 1992, 95; B J Oosterhoff, Jeremia (COT), Kampen 1990, 131; J A Thompson, The new international commentary on the Old Testament: The book of Jeremiah (NICOT) Grand Rapids 1980, 186; A van Selms, Jeremia (COT)(deel I), Nijkerk 1972, 60; F B Huey, Jeremiah Lamentations, (The new American commentary), Nashville 1993, 69; J P Hyatt \& S R Hopper, The Interpreter's Bible, New York 1956, 822; De Bijbel in nieuwe vertaling: Het Oude Testament van verklarende aantekeningen voorzien (deel II), Kampen 1954, 464; E Osty \& J Trinquet, La Bible (+ introductions et notes), Du Seuil, 1973, 1666; Adam Clarke's commentary on the Bible (abridged by R Earle), Grand Rapids 1976, 615.

2 Oosterhoff, $a w, 131$.

3 G Ch Aalders, De Profeet Jeremia (Korte Verklaring der Heilige Schrift), Kampen 1953, 52.

$4 \quad$ Van Selms, $a w, 60$.

5 De Bijbel in nieuwe vertaling: Het Oude Testament van verklarende aantekeningen voorzien (deel II), Kampen 1954, 464.

$6 \quad$ Osty \& Trinquet, $a w, 1666$.

$7 \quad$ Sien byvoorbeeld Jones, $a w, 95$.

$8 \quad$ Hyatt \& Hopper, $a w, 823$.

9 Adam Clarke's commentary on the Bible (abridged by R. Earle), Grand Rapids $1976,615$.

10 W H Jellie, The preacher's complete homiletic commentary on the Book of the prophet Jeremiah, Grand Rapids 1974, 33.

11 Thompson, $a w, 186$.

12 C P Gray, Beacon Bible Commentary: Jeremiah, Lamentations, Kansas City $1966,332$.

13 J L Green, Jeremiah-Daniel (The Broadman Bible Commentary), Nashville $1971,40$.

14 Oosterhoff $a w, 131$ is die enigste van al hierdie kommentatore wat na Egiptiese voorstellings verwys. Hy wys daarop dat daar afbeeldings in die Egiptiese kuns is van krygsgevangenes wat met hul hande bokant hul hoof saamgebind is. Hy voeg egter heel tereg by "Waarschijnlijk moet daar echter hier (= Jer 2:37) niet aan gedacht worden”. Maar ook hý laat na om al die Egiptiese voorstellings van 
mense wat ongedwonge hul hande op hul hoof hou, te betrek in die interpretasie van Jeremia 2:37.

15 Hierdie reliëfwerk is egter veel ouer en moet ongeveer $1300 \mathrm{vC}$ gedateer word.

16 Hierdie skildering dateer waarskynlik uit die laat XVIIIe-dinastie.

17 E A Nida \& J P Louw, Lexical semantics of the Greek New Testament (SBL Resources for Biblical Studies), Atlanta 1992, 18.

18 Vergelyk J P Louw, "Primary and secondary reading of a text", Neotestamentica 18, 18-25.

19 Vergelyk H F Stander, "Baptism and the interpretation of early Christian art", Hervormde Teologiese Studies 43/3(1987), 316-324. 